\title{
Trilha Verde da Maria Fumaça: patrimônio ferroviário e turismo no Vale do Jequitinhonha
}

\section{Trilha Verde da Maria Fumaça: railroad heritage and tourism in the Vale do Jequitinhonha (Brazil)}

\author{
Rosalia Aparecida Moreira, Hugo Rodrigues Araújo
}

\section{RESUMO}

Em 1986, foi criado nos Estados Unidos a Rails-to-Trails Conservancy, entidade sem fins lucrativos com a missão de contribuir para conservação do patrimônio ferroviário, transformando os ramais abandonados em trilhas ferroviárias destinadas, exclusivamente, para caminhantes, ciclistas e cavaleiros. Com essa perspectiva, há 15 anos iniciou-se uma mobilização comunitária para transformar o antigo Ramal Ferroviário Corinto-Diamantina, localizado no Vale do Jequitinhonha/MG, na primeira trilha ferroviária do Brasil, denominada Trilha Verde da Maria Fumaça - TVMF. Além da conservação dos bens ferroviários, a TVMF busca a dinamização da economia local através do Turismo de Base Comunitária. Este artigo corresponde a um estudo de caso da TVMF, de caráter exploratóriodescritivo. A pesquisa envolveu revisão bibliográfica e entrevista do gestor da ONG Caminhos da Serra, utilizando questionário semiestruturado. A análise qualitativa dos dados permitiu obter resultados que proporcionam o entendimento sobre a TVMF, contribuem para a abertura da discussão sobre trilhas ferroviárias no Brasil e fornecem informações para subsidiar aplicações práticas em outras ferrovias que se encontram abandonadas.

PALAVRAS-CHAVE: Turismo Ferroviário; Turismo Sustentável; Trilha Ferroviária.

\begin{abstract}
In 1986, the Rails-to-Trails Conservancy was created in the United States, a nonprofit organization with a mission to contribute to conservation of the railway heritage, turning extensions abandoned on rails trails, designed exclusively for walkers, cyclists and riders. With this perspective, 15 years ago a community began a mobilization to transform the old Railway Corinto-Diamantina, located in Vale do Jequitinhonha / MG, into the first rail trails in Brazil, called Trilha Verde da Maria Fumaça - TVMF. In addition to the conservation of rail assets, TVMF seeks to stimulate the local economy through the Community Based Tourism. This article is an exploratory and descriptive case study of TVMF. The research involved literature review and interview questions for the manager of the NGO Caminhos da Serra, by using semi-structured questionnaire. Through qualitative analysis of data it was possible to get results that provide an understanding of the TVMF, contribute to opening the discussion about rails trails in Brazil, and provide information to support practical applications in other railways that are abandoned.
\end{abstract}

KEYWORDS: Railway Tourism; Sustainable Tourism; Rails Trails. 


\section{Introdução}

As ferrovias tiveram início na Inglaterra, no começo do século XIX, e foram essenciais não apenas para a Revolução Industrial, mas para as transformações econômicas e sociais ocorridas no mundo. $O$ transporte ferroviário incentivou a expansão das indústrias em geral, principalmente porque ajudou a reduzir os custos de transporte de cargas, como minério, produtos agrícolas, fertilizantes, carvão, derivados de petróleo, dentre outros (SILVEIRA, 2003).

Além do transporte de carga as ferrovias também revolucionaram o sistema de transporte de passageiros, oferecendo melhores condições para as pessoas se deslocarem de um lugar ao outro. De tal modo, que o transporte ferroviário se encontra na gênese do advento da atividade turística moderna, que se deu a partir da iniciativa do inglês Thomas Cook, quando organizou a primeira excursão de trem para uma viagem de congressistas, em 1841 (PALHARES, 2002).

No Brasil, a primeira ferrovia foi inaugurada em 30 de abril de 1854, oficialmente denominada de Imperial Companhia de Navegação a Vapor e Estrada de Ferro de Petrópolis, mais tarde chamada de Estrada de Ferro Mauá, em homenagem ao seu criador, Irineu Evangelista de Souza, ou, simplesmente, Barão de Mauá. O objetivo principal da estrada era levar o café produzido no Vale do Paraíba ao cais de Magé e, de lá, de barco ao porto do Rio de Janeiro (PAULA, 2001; SILVA, 2014). O maior crescimento do sistema ferroviário brasileiro aconteceu entre 1908 e 1914, resultado, em grande parte, do afluxo de capital estrangeiro (PAULA, 2001, PALHARES, 2002).

No entanto, devido aos grandes incentivos para expansão da indústria automobilística e a ampliação do transporte aéreo na segunda metade do século $\mathrm{XX}$, as ferrovias começaram a perder importância e passaram a ser inutilizadas (PAULA, 2001; PROCHNOW, 2014). A partir da década de 60, 0 governo brasileiro colocou em prática um programa de erradicação dos ramais considerados "antieconômicos". Dessa forma, chegava ao fim a era ferroviária no Brasil, com a desativação de quase 10 mil quilômetros de ferrovias. O transporte de passageiros por ferrovias no Brasil foi praticamente extinto (à exceção de duas linhas operadas pela mineradora Vale) (PAULA, 2001).

Com esta extinção, o patrimônio ferroviário, principalmente as estações, passou a ser de responsabilidade da Secretaria do Patrimônio da União (SPU), que, nos últimos anos, tem buscado alternativas para assegurar a sua conservação (MAMEDE et al., 2008). Segundo Silva (2014), esses bens se constituem em edifícios e equipamentos que despertam interesse, seja pela monumentalidade e singularidade que representam, seja pela importância para a vida social e econômica dos centros em que se encontram.

Apesar de muitos desses bens encontrarem-se listados e reconhecidos como patrimônio cultural (CARMO, 2014), a cada dia, o conjunto do patrimônio ferroviário brasileiro torna-se mais pulverizado e deteriorado devido à falta de uma política eficaz voltada para a sua efetiva 
preservação (MAMEDE et al., 2008; CARMO, 2014). Segundo Carmo (2014, p.159), "as ações realizadas até o momento apresentam-se claramente insuficientes pela ausência de uma visão global do patrimônio ferroviário, o que torna o resgate da memória ferroviária distante de se concretizar".

A solução encontrada por muitos países que enfrentaram situação semelhante foi a implantação de rails trails (trilhas ferroviárias - tradução nossa), ou seja, a transformação de antigos ramais ferroviários abandonados em trilhas estruturadas para caminhantes, ciclistas e cavaleiros (BEETON, 2006). Essa ideia surgiu na década de 1980 nos Estados Unidos da América-EUA, a partir da criação da Conservancy Railsto-Trails, uma entidade sem fins lucrativos de âmbito nacional, que trabalha em prol da consolidação de uma rede de trilhas ferroviárias no país. Por seus registros, atualmente existem nos EUA mais de 35 mil quilômetros de trilhas ferroviárias (REIS e JELLUM, 2012). Entretanto, hoje também há trilhas ferroviárias em diversos países da Europa, Canadá, Austrália, Nova Zelândia, dentre outros (MOORE et al., 1994). Assim como ocorre nos EUA, na maioria dos casos a gestão das trilhas ferroviárias está sob responsabilidade de uma associação de moradores locais comprometidos, principalmente, com a preservação da memória do ramal ferroviário (BEETON, 2006).

No Brasil, nomeadamente no Vale do Jequitinhonha em Minas Gerais, existe uma região habitualmente caracterizada pela sociedade brasileira como carente e atrasada, há 15 anos conta com a Organização Não Governamental - ONG Caminhos da Serra tem envidado esforços para implantar de forma participativa a primeira trilha ferroviária do país, denominada de Trilha Verde da Maria Fumaça - TVMF. Trata-se de um projeto que visa salvaguardar o patrimônio histórico e cultural que restou do antigo Ramal Ferroviário Corinto-Diamantina e incentivar o Turismo de Base Comunitária - TBC, nos moldes que supõem o protagonismo das comunidades locais na gestão da atividade e na oferta de bens e serviços turísticos (BARTHOLO et al., 2009).

Há vários trechos de ferrovias abandonadas no Brasil que são tradicionalmente utilizados por caminhantes e ciclistas (CARMO, 2014), mas que estão longe de se estabelecerem no formato de uma rail trail. Há também um projeto em fase de concepção, que prevê a transformação da Estrada de Ferro Central do Recife, especificamente o trecho RecifeGravatá, em uma trilha ferroviária nos moldes das rails trails. Esse projeto está inserido no Programa Nacional de Desenvolvimento do Turismo (PRODETUR) em Pernambuco, mas ainda está em processo de aprovação interna da fonte financiadora, o Banco Interamericano de Desenvolvimento (BID) (ALVES, 2014). Além dos moldes das rails trails, algumas ferrovias, também, são utilizadas para operação de trens turísticos. Em geral, são passeios curtos, de apelo histórico e/ou paisagístico, próximos de grandes cidades ou áreas de importância turística (CARMO, 2014). Sendo assim, a TVMF pode ser considerada uma iniciativa pioneira e única no país.

Diante disso, o objetivo principal desse estudo foi reunir informações para compreender melhor a proposta da TVMF e apresentar uma 
contextualização dos principais acontecimentos ocorridos desde 0 surgimento do projeto até o atual momento.

Essa investigação caracteriza-se como um estudo de caso, de caráter exploratório-descritivo. Portanto, iniciou-se com a revisão bibliográfica a respeito da relação do patrimônio cultural com o turismo, o turismo de base comunitária, as rails trails (trilhas ferroviárias), e o antigo Ramal Ferroviário Corinto-Diamantina. Em seguida, foi realizada entrevista com o gestor da ONG Caminhos da Serra, utilizando questionário semiestruturado com tópicos gerais pré-definidos, mas permitindo inserir perguntas ao longo da conversação que não estavam previstas. Segundo Ludke e André (1986), a grande vantagem da entrevista sobre outras técnicas é que permite correções, esclarecimentos e adaptações que a tornam eficaz na obtenção das informações desejadas. A entrevista foi gravada, mediante consentimento prévio do entrevistado, em seguida, transcrita na íntegra. Por fim, a apreciação e a discussão do conteúdo das mensagens ocorreram de forma qualitativa. De acordo com Alves e Silva (1992), a análise qualitativa se caracteriza por buscar uma apreensão de significados na fala dos sujeitos, interligada ao contexto em que eles se inserem e delimitada pela abordagem conceitual (teoria) do pesquisador, trazendo à tona, na redação, uma sistematização coerente e fluida que encaminhe o leitor para a compreensão, análise e crítica do objeto de estudo.

Por fim, são apresentados os resultados e discutidos com base na literatura. Os resultados obtidos proporcionam o entendimento sobre a TVMF, contribuem para a abertura da discussão sobre "trilhas ferroviárias" no Brasil e, ao mesmo tempo, fornecem informações para subsidiar aplicações práticas em outros ramais ferroviários que se encontram abandonados no país.

\section{Patrimônio cultural e turismo}

A palavra patrimônio é derivada do latim patrimonium, o qual se relaciona com tudo que é pertencente a pater, o pai de família. Nesse caso, visto como algo herdado de gerações passadas. Em se tratando do "patrimônio cultural", a herança consiste em bens, valores e tradições que representam um vínculo compartilhado de identidade, por meio do sentimento de pertencimento a uma determinada comunidade (PAES, 2009).

De acordo com a Organização das Nações Unidas para a Educação, a Ciência e a Cultura - UNESCO (acrônimo de United Nations Educational, Scientific and Cultural Organization), o patrimônio cultural engloba 0 patrimônio cultural tangível, que se subdivide em bens móveis (pinturas, esculturas, moedas, manuscritos etc.), bens imóveis (monumentos, sítios arqueológicos e outros), e bens subaquáticos (naufrágios, ruínas e cidades submarinas); e o patrimônio cultural intangível (tradições orais, espetáculos artísticos, rituais etc.) (BRASIL, 2010).

$\mathrm{Na}$ Conferência Mundial sobre Políticas Culturais, organizada pelo Conselho Internacional de Monumentos e Sítios (ICOMOS) em 1985 no México, definiu-se que o patrimônio cultural engloba "as obras materiais e não materiais que expressam a criatividade desse povo: a língua, os ritos, as 
crenças, os lugares e monumentos históricos, a cultura, as obras de arte e os arquivos e bibliotecas" (CAVALCANTE, 2011, p. 8).

De acordo com Paes (2009), as origens da concepção de patrimônio possuem inúmeras raízes, e todas se firmam na ideia de preservação da memória coletiva. De forma geral, o patrimônio cultural compreende todos os elementos que determinam a identidade de um grupo social, assim como o diferencia dos demais.

Desse modo, ao se levar em consideração os diversos tipos de patrimônio, todos têm sua importância de preservação. Afinal, todos os patrimônios estão diretamente ligados a uma memória que identifica um local, uma comunidade, a educação, os hábitos e tudo referente à existência de uma história (CAVALCANTE, 2011).

Por outro lado, Barreto (2000) ressalta que se deve associar a preservação do patrimônio com o desenvolvimento local. Nesse sentido, o turismo tem contribuído de alguma forma para a preservação e recuperação de identidades locais e, ao mesmo tempo, o surgimento de novas oportunidades resultam em benefícios socioeconômicos efetivos para a população local. Entretanto, Portuguez (2004) ressalta que o fato de utilizar o patrimônio como fonte de recursos demanda um maior cuidado para que este não seja danificado pela ação de usufruí-lo desordenadamente. Isso implica pensar na conservação apropriada e, também, em recursos de sustento para a atividade turística.

Além disso, segundo Coriolano (2006) a conscientização e a participação efetiva da população local nesse processo são essenciais para assegurar o uso do patrimônio de maneira correta. Afinal, a comunidade é a verdadeira responsável e guardiã de seus valores culturais. Caso a comunidade, por qualquer motivo, pare de estabelecer os laços históricos necessários e não se identifique mais com os seus bens de memória, os significados serão perdidos e o seu patrimônio deixará de cumprir uma função social essencial que é a manutenção da identidade local.

Portanto, não se pode pensar em proteção do patrimônio cultural, sem que o mesmo seja do interesse da própria comunidade. A utilização turística dos bens culturais pressupõe sua valorização, promoção e permanência no tempo como símbolos de memória e de identidade. Valorizar e promover significa difundir o conhecimento sobre esses bens, facilitar seu acesso e usufruto a moradores e turistas (BARRETO, 2000).

\section{Turismo de Base Comunitária como alternativa ao modelo de turismo convencional}

O Turismo de Base Comunitária - TBC, também denominado Turismo de Base Local, surgiu de uma série de debates sobre a necessidade de criação de novas formas de turismo, construídas em um modelo mais justo e equitativo, que levasse em consideração a sustentabilidade ambiental e que colocasse a população local no centro do planejamento, da implantação e do monitoramento das atividades turísticas (BARTHOLO JUNIOR, 2009). 
O TBC propõe que os próprios moradores planejem e controlem o desenvolvimento turístico na comunidade, sendo os benefícios voltados de forma justa para todos os envolvidos (SAMPAIO e OYARZÚM, 2006). De acordo com Araújo e Gelbcke (2008, p.366), trata-se de "uma estratégia de desenvolvimento para grupos com menores condições de ingressarem de maneira autônoma na cadeia produtiva do turismo".

Segundo o Ministério do Turismo (2008), o TBC corresponde a um modelo de desenvolvimento turístico, orientado pelos princípios da economia solidária, associativismo, valorização da cultura local, e, principalmente, protagonizado pelas comunidades locais, visando à apropriação por parte dessas dos benefícios advindos da atividade turística.

Sampaio et al., (2006) ressalta que o TBC acontece quando há uma rede horizontal de cooperação na comunidade, ou seja, todos os membros auxiliam para o desenvolvimento da atividade, sem ordem hierárquica. Para Coriolano (2006), a participação da comunidade em projetos de TBC se dá a partir do momento em que a comunidade se apropria do turismo e do projeto que pretende ser implantado.

Coriolano (2006) ainda destaca que a inserção do TBC na comunidade pode proporcionar aos moradores certa independência de ordem econômica, social e ambiental. Afinal, permite que a população local não seja "explorada", por exemplo, por grandes redes hoteleiras. Nesse sentido, O TBC representa uma oportunidade de a comunidade trabalhar voltada para a oferta de produtos e serviços que não seja apenas voltada ao consumo, mas à troca de experiências, fortalecimento de laços de amizade e valorização cultural (CORIOLANO, 2006).

No Brasil, atualmente, existem numerosos projetos e programas de TBC. A Prainha de Canto Verde, localizada no município de Beberibe, no Ceará, é considerada um dos casos de sucesso pioneiros de TBC no país. Essa comunidade tornou-se um exemplo por causa da grande participação dos atores locais que se engajaram no projeto e criaram a Associação Comunitária dos Moradores da Prainha do Canto Verde, que desenvolve atividades relacionadas ou não com o turismo (CORIOLANO, 2006). Segundo Mendonça e Irving (2004), o que difere a Prainha do Canto Verde das demais localidades que fracassaram na tentativa de desenvolver o TBC é o envolvimento, a organização, a união da comunidade na prática da atividade turística.

Apesar de o envolvimento dos moradores ser imprescindível para o desenvolvimento do TBC, também, é muito importante o fomento das entidades públicas, pois esse modelo de gestão comunitária não exclui a importância de apoio e recursos para os fins (SANSOLO; BURSZTYN, 2009). Apesar disso, o TBC no Brasil carece de mais apoio de entidades públicas, pois os locais que desenvolvem esse tipo de turismo, geralmente, são carentes de infraestruturas básicas para os próprios moradores. Além disso, o turismo não é a principal fonte de renda dos moradores locais, embora a renda advinda das atividades turística pudesse contribuir muito para melhoria da qualidade de vida da comunidade (SANSOLO; BURSZTYN, 2009). 
Diante do desafio de aumentar e diversificar a oferta turística brasileira, associada ao objetivo de promover o turismo como vetor de desenvolvimento socioeconômico do país, o TBC representa uma alternativa singular para algumas regiões de compatibilizar a oferta de produtos e serviços turísticos diferenciados, com a promoção de melhorias na qualidade de vida das comunidades locais (BARTHOLO JUNIOR, 2009).

\section{Trilhas ferroviárias: origem e caracterização}

Em 1986 nos Estados Unidos, diante do crescente abandono das ferrovias e da improvável reativação de muitos ramais, foi fundada em Washington a Rails-to-Trails Conservancy - RTC, organização sem fins lucrativos com a missão de criar no país uma rede de rail trails (trilhas ferroviárias - tradução nossa) (MOORE et al., 1994). A proposta da RTC foi transformar as vias férreas desativadas em caminhos do tipo "multiuso", destinados exclusivamente para caminhantes, ciclistas e cavaleiros. Dessa forma, esperava-se gerar oportunidades de novos negócios, incentivar a prática de atividades saudáveis ao ar livre e, principalmente, conseguir captar recursos para manter conservado o patrimônio ferroviário (BEETON, 2006).

A RTC identificou o potencial que os ramais ferroviários ofereciam pelo fato de as locomotivas não conseguirem fazer curvas fechadas, muito menos subir grandes inclinações. Assim sendo, as vias férreas desativadas, quando em desuso, tornam-se caminhos ideais para qualquer pessoa, sem limitação de idade ou capacidade física, percorrer longas distâncias atravessando, até mesmo, terrenos íngremes como serras, colinas e escarpas (MOORE et al., 1994).

Além das belezas naturais, ao longo do percurso podem ser apreciados os elementos que compõem o patrimônio histórico e cultural das ferrovias, como os túneis, os pontilhões, as estações, bem como as influências deixadas no modo de vida das populações que conviveram com a chegada e a partida de pessoas e com os processos de carga e descarga de produtos (REIS; JELLUM, 2012). Tais atributos atraem pessoas interessadas em desfrutar a natureza, conhecer a história, a geografia, ou apenas visitar lugares ao fugir de estradas convencionais (ABELLÁN, 2011).

A ideia rapidamente espalhou-se pelo mundo. Atualmente, além da RTC nos Estados Unidos, há trilhas ferroviárias implantadas em diversos outros países, como: Austrália, Nova Zelândia, Canadá, Inglaterra, Irlanda, Alemanha, França, Espanha, dentre outros (BEETON, 2006; REIS; JELLUM, 2012). As trilhas ferroviárias também podem ser instaladas ao lado de ramais que se encontram em atividade, sendo, assim, chamadas "trilhos com trilhas". Alguns países utilizam o termo trail way em vez de rail trails. $\mathrm{Na}$ Espanha, os ramais convertidos em trilhas são chamados de "vías verdes" (MARTÍN, 2014).

A conversão dos ramais abandonados em trilhas ferroviárias compreende a instalação de sinalização indicativa e interpretativa, bebedouros, mesas de piquenique, mirantes, assentos, banheiros, pontos de acesso gratuito à internet, dentre outras comodidades (MARTíN, 2014). 
Algumas trilhas oferecem condições para, até mesmo, pessoas com mobilidade reduzida percorrê-las. Os projetos normalmente são financiados pelo poder público em parceria com a iniciativa privada e contam com o apoio de entidades do terceiro setor, como associações, fundações e ONGs, para gestão e manutenção das trilhas ferroviárias (REIS; JELLUM, 2012).

No geral, cada trilha ferroviária dispõe de uma página na internet contendo informações de restaurantes, opções de hospedagem, agências bancárias, lojas que alugam ou reparam bicicletas, alternativas de regresso no final do passeio, além de imagens, vídeos, mapas e relatos de pessoas que fizeram o percurso. A rede de trilhas ferroviárias de alguns países, como Estados Unidos e Austrália, disponibilizam aplicativo de smarthphone para as pessoas terem acesso a essas e outras informações (REIS; JELLUM, 2012).

\section{Ramal Ferroviário Corinto-Diamantina: da construção ao abandono}

O Ramal Ferroviário Corinto-Diamantina foi inaugurado em 1914, pela Estrada de Ferro Vitória a Minas - EFVM, que, em 1923, o repassou à Estrada de Ferro Central do Brasil. A ferrovia tinha 145 quilômetros de extensão, que interligava os municípios de Diamantina, Gouveia, Monjolos, Santo Hipólito, Curvelo e Corinto, localizados no centro-norte de Minas Gerais. O ponto inicial era a estação de Corinto (a $607 \mathrm{~m}$ de altitude) e 0 ponto final a estação de Diamantina (a $1.261 \mathrm{~m}$ de altitude). No trecho entre elas havia outras estações, como a de Roça do Brejo, Santo Hipólito, Monjolos, Rodeador, Conselheiro Mata, Barão de Guaicuí e Guinda (Figura 1) (GIESBRECHT, 2015).
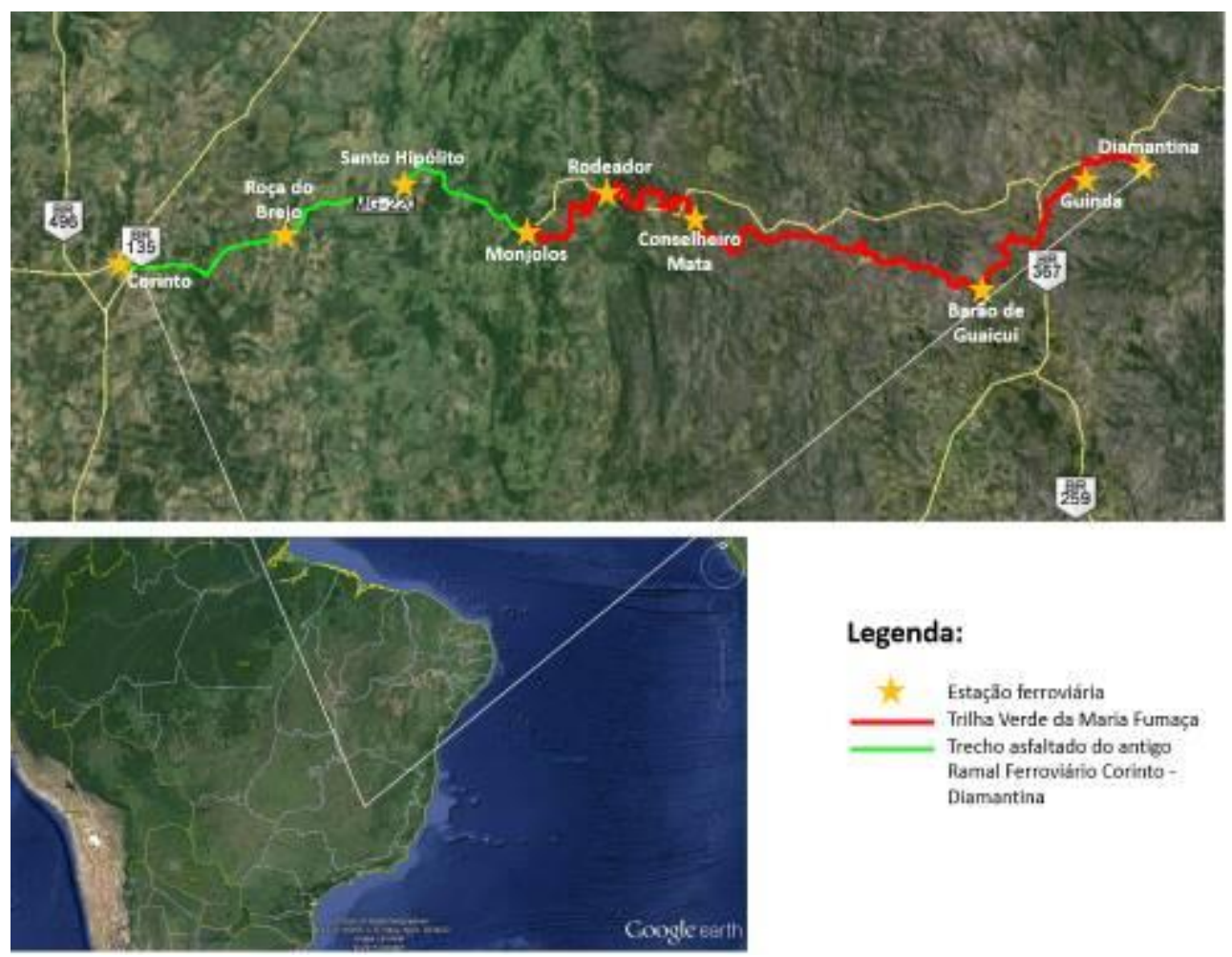

Legenda:

Estação ferrowiária

Trilha Verde da Maris Fumaça

Trecho asfaltado do antigo

Ramal Ferrovíbrio Corinto-

Diamsntina

Figura 1: Localização da Trilha Verde da Maria Fumaça. Fonte: Elaboração própria. Figure 1: Trilha Verde da Maria Fumaça location. Source: Own elaboration. 
A construção do ramal teve por intuito alavancar a economia da região que, apesar de possuir muitas riquezas, estava geograficamente isolada (GIESBRECHT, 2015). Diamantina, por exemplo, era exaltada pela sua beleza e considerada uma cidade avançada, pois já naquela época possuía escolas em todos os seus distritos, além de um ginásio de ensino secundário, uma escola normal de formação de professores, um seminário para formação de ministros eclesiásticos, uma fábrica de tecidos, dentre outros atributos que justificavam a necessidade de facilitar o seu acesso (MARTINS, 2008).

Foi um período de grande expectativa para os moradores da região, que puderam acompanhar todo o processo através das notícias publicadas nos jornais locais, como o Jornal do Jequitinhonha, publicado a partir de 1869. A imprensa jornalística registrou todos os acontecimentos relacionados ao ramal, desde o anúncio da estrada de ferro até a sua inauguração. Havia momentos em que eram retratados o orgulho e o prestígio da região em receber um impulso para o progresso, mas também o desapontamento com os atrasos das obras, abusos, desvio de verbas e exploração (SOUZA, 1993).

O traçado do ramal proporcionava o contraste de diferentes cenários com rara beleza, pois iniciava no sertão de Minas Gerais e serpenteava por serras e riachos da bacia do Rio das Velhas, até chegar às vertentes do Rio Jequitinhonha, na Serra do Espinhaço. Todavia, o ramal funcionou somente até o início dos anos 1970, quando foi desativado o transporte de passageiros e cargas (GIESBRECHT, 2015). Os acontecimentos mais marcantes da história do Ramal Ferroviário Corinto-Diamantina são apontados em ordem cronológica no Quadro 1.

Quadro1: Acontecimentos mais marcantes da história do Ramal Ferroviário CorintoDiamantina. Fonte: Elaborado com base em Giesbrecht (2015).

Chart 1: Most remarkable events in the history of railway branch Corinto - Diamantina.

Source: Based on Giesbrecht (2015).

\begin{tabular}{|c|c|}
\hline Ano & Acontecimento \\
\hline 1876 & Início dos estudos para construção de uma ferrovia entre Vitória-ES e Diamantina-MG. \\
\hline 1889 & $\begin{array}{l}\text { Foi anunciado a Diamantina que ela receberia uma estrada de Ferro, essa notícia } \\
\text { promoveu uma imensa alegria aos diamantinenses, eles realizaram festas ao } \\
\text { receberem a notícia, acreditavam num futuro melhor para Diamantina. }\end{array}$ \\
\hline 1895 & $\begin{array}{l}\text { Assinatura do contrato entre o Ministério da Indústria e Viação e a Companhia Estrada } \\
\text { de Ferro Vitória a Minas para a construção da via férrea Vitória a Diamantina em Belo } \\
\text { Horizonte. Essa notícia foi recebida com muita alegria pelos diamantinenses. }\end{array}$ \\
\hline 1903 & $\begin{array}{l}\text { Chega a Vitória o material para a construção da Estrada de Ferro Vitória a Diamantina. } \\
\text { Acontece em Vitória a cerimônia onde é colocada a primeira estaca de locação da via } \\
\text { férrea. }\end{array}$ \\
\hline 1909 & Início da construção do ramal de Diamantina. \\
\hline 1910 & Inaugurações das primeiras estações. \\
\hline 1911 & $\begin{array}{l}\text { Comunicado de multa à companhia Vitória a Minas pelo atraso nas obras do Ramal. } \\
\text { Início da construção da Estação de Diamantina. }\end{array}$ \\
\hline 1913 & Inauguração da Éstação de Guinda. \\
\hline 1914 & Inauguração do ramal de Diamantina, no dia 5 de maio. \\
\hline 1920 & Transferência do ramal de Diamantina para a EFCB. \\
\hline 1973 & Desativação do Ramal. \\
\hline
\end{tabular}


Após a desativação do ramal, os trilhos foram arrancados e parte dos terrenos foi doada ou vendida pela rede ferroviária. Os bens imóveis e móveis, com a inclusão de locomotivas, vagões, pontilhões, casas de turma ${ }^{1}$ estações, passaram a pertencer à União, além de mobiliários, como relógios, sinos, telégrafos e acervos documentais. Com o passar dos anos e o abandono do governo, os dormentes foram saqueados, alguns trechos do ramal invadidos e todos os demais bens pouco a pouco se degradaram devido à ação do tempo (SOUZA, 1993).

No princípio dos anos 2000, a ONG Caminhos da Serra, juntamente com um grupo de moradores da região começaram uma mobilização para tentar resguardar o que restava de lembrança do antigo Ramal Ferroviário Diamantina-Corinto. Assim, surgiu a ideia da Trilha Verde da Maria FumaçaTVMF.

\section{Resultados e discussão}

A ONG Caminhos da Serra está localizada na cidade de Gouveia, Minas Gerais. Foi fundada em 31 de março de 1999 com a missão de promover ações que visem a conservação e valorização do patrimônio cultural, histórico e natural, bem como o desenvolvimento comunitário dentro dos princípios do associativismo. Em 2000, preocupada com o patrimônio do antigo Ramal Ferroviário Corinto-Diamantina, a Caminhos da Serra organizou a primeira expedição de reconhecimento desses bens (SANTOS, 2015).

Nessa oportunidade, foi constatado que, ao longo da via férrea, além das edificações que sobreviveram ao abandono, como as estações, os pontilhões e algumas casas de turma, o conjunto de bens que compunham o patrimônio do ramal incluía também cachoeiras, rios, serras, cavernas, dentre outros atrativos naturais. Surgiu, então, a proposta de transformar o ramal abandonado em uma trilha ferroviária, nos moldes das rail-trails espalhadas pelo mundo. Essa ideia foi concebida no projeto denominado de "Trilha Verde da Maria Fumaça - TVMF", que tem por objetivo criar uma rede de preservação da memória do Ramal Ferroviário Corinto-Diamantina e, ao mesmo tempo, criar possibilidades de novos negócios, lazer, conhecimento e valorização das comunidades (SANTOS, 2015).

A ideia é estruturar o antigo ramal ferroviário dando condições de ser percorrido com segurança por caminhantes, ciclistas e cavaleiros, e implantar o TBC nas comunidades localizadas ao longo do trecho. Assim, deu-se início a uma série de reuniões com instituições públicas e privadas, com o intuito de sensibilizar as pessoas acerca do valor histórico, artístico e cultural dos bens móveis e imóveis oriundos da extinta ferrovia (SANTOS, 2015).

Em 2005, foi realizada uma expedição de Diamantina a Corinto, com o escopo de percorrer a pé toda a extensão do ramal para elaborar um diagnóstico participativo da TVMF. Além da ONG Caminhos da Serra, participaram desta expedição os moradores das comunidades interessados em contribuir com o projeto e representantes de entidades públicas e privadas, como: o Instituto Brasileiro do Meio Ambiente e dos Recursos 
Naturais Renováveis - IBAMA; o Ministério de Turismo - MTUR; o Instituto Estadual de Florestas - IEF; a Empresa de Assistência Técnica e Extensão Rural do Estado de Minas Gerais - EMATER/MG; a Secretaria de Estado de Turismo de Minas Gerais - SETUR/MG; as Prefeituras Municipais de Diamantina e Gouveia; o Corpo de Bombeiros; o Serviço Brasileiro de Apoio às Micro e Pequenas Empresas - SEBRAE, o Serviço Nacional de Aprendizagem Comercial - SENAC e a Companhia de Saneamento de Minas Gerais - COPASA (SANTOS, 2015).

Essa expedição é um marco na história da TVMF, pois, pela primeira vez ocorreu uma mobilização efetiva de diversas instituições, ao mesmo tempo, em prol do projeto. Ao longo de cinco dias, os participantes puderam conhecer os atrativos naturais e culturais da via férrea, visualizar as possibilidades de aproveitamento turístico e os benefícios que poderiam ser gerados para a sociedade em geral, com a implantação da trilha ferroviária (SANTOS, 2015).

O diagnóstico ressaltou os cuidados necessários durante a implantação da TVMF para impedir ou minimizar os impactos negativos que poderiam ser causados, principalmente no modo de vida das comunidades. Além disso, apontou medidas necessárias com base nas deficiências identificadas ao longo do percurso, como: revitalização das estações; reforma dos pontilhões; sinalização do ramal (indicativa e interpretativa); contenção das erosões; remoção dos lixos; sensibilização e capacitação dos moradores locais; dentre outras. Uma decisão importante compartilhada pelo grupo foi a delimitação da área de atuação do projeto. Ficou definido que a TVMF se iniciaria na estação de Diamantina e terminaria na estação de Monjolos, uma vez que, a partir deste ponto, o ramal encontra-se totalmente descaracterizado, por ter sido asfaltado e convertido em rodovia (SANTOS, 2015).

Contudo, após a expedição, as responsabilidades compartilhadas entre os participantes não foram cumpridas da forma esperada. A expectativa era que cada instituição assumisse uma demanda específica para viabilizar a TVMF, o que não ocorreu e dificultou o desenvolvimento do projeto durante um longo tempo. Com o passar dos anos, as informações contidas no diagnóstico, inevitavelmente, ficaram desatualizadas. Desse modo, em 2010 o Circuito Turístico dos Diamantes ${ }^{2}$, em parceria com a ONG Caminhos da Serra, contratou um técnico para refazer o levantamento e a avaliação do patrimônio natural, histórico e cultural da TVMF, bem como apontar as medidas necessárias para implantação e manutenção da trilha ferroviária. Depois da conclusão desse estudo, as articulações com instituições públicas e privadas voltaram a ganhar força em busca de apoio para viabilização do projeto (SANTOS, 2015).

Em 2011, o Ministério Público de Minas Gerais firmou um termo de compromisso entre os municípios de Diamantina, Gouveia e Monjolos, tendo como anuentes o Instituto de Patrimônio Histórico e Artístico Nacional IPHAN e a Secretaria de Patrimônio da União. Os municípios ficaram obrigados a cumprir medidas para proteção e preservação do antigo Ramal Ferroviário Corinto-Diamantina (SANTOS, 2015). 
Com essa medida, viu-se a necessidade de instituir um grupo de trabalho para coordenar a implantação e o cumprimento dos objetivos da trilha ferroviária, com a preocupação de harmonizar os interesses dos diversos atores sociais envolvidos. Assim, em 2012 foi criado o Conselho Consultivo e Propositivo da Trilha Verde da Maria Fumaça, denominado de CONTRILHA. O conselho possui representantes do setor público, setor privado e da sociedade civil pertencente aos três municípios que fazem parte da TVMF. Uma das primeiras ações do CONTRILHA foi providenciar a elaboração do logotipo da TVMF, com o objetivo de estabelecer a sua identidade visual e facilitar 0 seu reconhecimento. Além disso, 0 CONTRILHA tem realizado oficinas de planejamento para buscar caminhos para desenvolver a atividade turística, aliada a fatores que contribuam para a valorização da cultura local e a conservação da natureza (SANTOS, 2015).

Em 2013, o Conselho do Estado de Minas Gerais - COPAM/Unidade Regional Colegiada Jequitinhonha determinou que a mineradora Anglo American financiasse a elaboração e execução do Projeto Técnico de Estruturação da Trilha Verde da Maria Fumaça, como medida compensatória imposta pelo Ministério Público. Assim sendo, foram realizadas obras de intervenção física em áreas prioritárias do percurso, com o intuito de sanar problemas decorrentes, principalmente, de processos erosivos. Além disso, os pontilhões foram assoalhados e, a eles, foram adicionadas redes de proteção para passagem segura de caminhantes e ciclistas. O projeto prevê ainda a confecção e instalação de placas de sinalização (SANTOS, 2015).

Depois disso, a trilha passou a ser divulgada com maior destaque nas campanhas publicitárias do Circuito Turístico dos Diamantes. Atualmente, mesmo com alguns elementos do projeto ainda não finalizados, a TVMF já tem sido bastante utilizada pelos moradores da região, principalmente para a prática de caminhadas e passeios ciclísticos. Como ainda não há monitoramento constante, não é possível saber o número exato de frequentadores. Contudo, na internet encontram-se facilmente vídeos, imagens e depoimentos de pessoas que realizaram o percurso (SANTOS, 2015).

Em 2014, foi realizado em Monjolos o Seminário comemorativo dos 100 anos de inauguração do Ramal Ferroviário Corinto-Diamantina. Durante esse evento, foram apresentadas para a comunidade as ações realizadas até então pelo CONTRILHA e as metas para 2016. Aproveitou-se também a oportunidade para serem realizadas duas oficinas de interpretação ambiental (SANTOS, 2015).

Outros projetos relacionados diretamente com a trilha ferroviária estão em andamento, como a formação de receptivos familiares nas comunidades de Barão de Guaicuí e Monjolos, e o Ponto de Memória, denominado de "A foto dentro da foto da antiga estrada de ferro Diamantina-Curralinho ${ }^{3}$ : a memória no tempo presente". Esse projeto prevê a realização de cinco minicursos e cinco exposições nas comunidades situadas no entorno das antigas estações ferroviárias. Os minicursos buscam abordar a história e o patrimônio cultural ligado à ferrovia, com a utilização de recursos tecnológicos digitais para produzir imagens e animações que serão apresentadas às comunidades durante as exposições (SANTOS 2015). 
Em 2015, o projeto TVMF completou 15 anos de existência. Apesar de todos esses avanços, os desafios para concretizar efetivamente a TVMF ainda são grandiosos. Como não há uma equipe responsável pelo monitoramento constante da trilha, são frequentes as denúncias de novas invasões do terreno que pertence ao ramal, assim como, os flagrantes de motociclistas e "jeepeiros" que não respeitam a destinação exclusiva da trilha para tráfego não motorizado. É também necessária a manutenção regular e efetiva dos bens móveis e imóveis da TVMF, a fim de evitar a deterioração. Com relação à divulgação, a TVMF dispõe de uma página no Facebook, mas faltam ainda folhetos impressos com mapa e descrição do percurso, assim como, uma página na internet. Pretende-se também elaborar um passaporte da TVMF (SANTOS, 2015).

Uma das expectativas do CONTRILHA é transformar as estações ferroviárias em pontos de apoio. Nesses locais, as pessoas vão ter acesso a todos os tipos de informações relacionadas à TVMF, e outras facilidades, como internet, água potável e banheiros. Um espaço será destinado para exposição de fotografias e peças que compõem o patrimônio ferroviário. Além disso, haverá uma loja oferecendo lembranças da TVMF, como cartões postais, camisetas, bonés, livros, chaveiros, canecas, dentre outras (SANTOS, 2015).

Diante da contextualização da TVMF ora apresentada, pode-se afirmar que o projeto está conseguindo atingir o objetivo de contribuir para conservação do patrimônio do antigo Ramal Ferroviário Corinto-Diamantina. Conforme Portuguez (2004), todos os bens, do tipo material ou imaterial, em que constam os significados histórico, cultural e/ou sentimental, devem ser preservados a partir do contexto indicador de que eles sejam fatores determinantes no presente ou no futuro. E, ainda, que sejam adequados a contribuir para o entendimento e a inclusão da identidade cultural social produzida por ela.

Ao mesmo tempo, a TVMF está criando oportunidades de revitalização da economia local através do TBC. Afinal, esse estudo permitiu verificar que, ao contrário da forma usual que o turismo se desenvolve em função dos turistas e dos empreendimentos turísticos, deixando as comunidades anfitriãs alheias ao processo (CORIOLANO, 2006), a TVMF incentiva o protagonismo das comunidades locais na gestão do projeto. Conforme Bartholo Junior et al. (2011), a atuação da comunidade como protagonista deve acontecer por meio da liberdade de participar espontaneamente dos processos de tomada de decisão, o que implica na sua responsabilização pelo cenário futuro desenhado e definido como objetivo a ser alcançado por todos.

Dessa forma, acredita-se que a TVMF se manterá vigente por tempo indeterminado, especialmente, pelo fato de não estar vinculada a nenhuma entidade ou governo específico. A TVMF é uma iniciativa da comunidade e por ela própria coordenada, de forma coletiva e transparente, através do CONTRILHA. Assim, aos poucos a TVMF vai se consolidando, nem tão devagar, nem tão depressa, mas no tempo certo, assim como deve ser para as comunidades locais assimilarem as ideias e se adaptarem às mudanças necessárias. 


\section{Considerações finais}

O presente trabalho demonstrou a importância que o patrimônio ferroviário pode ter na diversificação da oferta turística do Brasil, através da implantação de trilhas ferroviárias. Essa iniciativa, além de contribuir para solucionar os problemas decorrentes do abandono dos bens ferroviários, incentiva o desenvolvimento do TBC nestes locais, gerando oportunidades de renda complementar para as populações.

É necessário investimento na diversificação da oferta turística para o desenvolvimento socioeconômico do país. A valorização e preservação de antigos ramais ferroviários permitem essa diversificação, promovendo a interação entre as comunidades locais e turistas.

Em se tratando da TVMF, verificou-se que as conquistas mais relevantes vieram somente 10 anos após as primeiras mobilizações em prol do projeto. A persistência das lideranças comunitárias, apoiadas pelos moradores locais, que participaram da idealização foi, e continua sendo, fundamental para mantê-lo vigente por tanto tempo, mesmo sem contar com recursos técnicos e financeiros suficientes para isso.

Diante da falta de fiscalização e do descaso com o patrimônio ferroviário que já causaram perdas irrecuperáveis para o Brasil, a TVMF surge como uma referência para inovar as discussões em torno da conservação dos antigos ramais que se encontram abandonados. Assim, espera-se que este estudo sirva para sensibilizar e difundir essa iniciativa no meio acadêmico e demais áreas da sociedade ao motivar novas pesquisas, concernentes ao interesse da comunidade local, das lideranças locais, dos tomadores de decisões e sociedade em geral em preservar seu patrimônio ferroviário e as formas de executar tal empreendimento ou, o que seria uma lástima, deixar que a memória dele, parte da história das comunidades locais, se evanesça pela ação implacável do tempo.

\section{Referências bibliográficas}

ABELLÁN, F. C. Los ferrocarriles olvidados. Reconversión y reinvención como instrumentos de revitalización recreativa y turística: el Baeza-Utiel a su paso por la provincia de Albacete. Cuadernos de turismo, v.27, p.205-225, 2011.

\begin{tabular}{l} 
ALVES, C. Na Estrada de Ferro Central de Pernambuco ainda há 35 \\
estações. $\quad 2014 . \quad$ Disponível \\
<http://jconline.ne10.uol.com.br/canal/cidades/geral/noticia/2014/11/08/na- \\
estrada-de-ferro-central-de-pernambuco-ainda-ha-35-estacoes- \\
\hline 155080.php>. Acesso em: 05 de julho 2016.
\end{tabular}

ALVES, Z.M.M.B.; SILVA, M.H.G. Análise qualitativa de dados de entrevista: uma proposta. Paidéia (Ribeirão Preto), n.2, p.61-69, 1992.

ARAÚJO, G.P; GELBCKE, D.L. Turismo comunitário: Uma perspectiva ética e educativa de desenvolvimento. Revista Turismo Visão e Ação Eletrônica, v.10, n.3. p.357 - 378, 2008. 
BRASIL. Turismo Cultural: orientações básicas. Brasília: Ministério do Turismo, 2010.

BRASIL. MINISTÉRIO DO TURISMO. Chamada Pública MTUR n. 001/2008 - Apoio às iniciativas de turismo de base comunitária. Brasília, $2008 . \quad$ Disponível em: $<$ http://www.turismo.gov.br/export/sites/default/turismo/convenios contratos/ selecao projetos/Edital Chamada Pxblica de Projetos 0012008.pdf>.

Acessado em: 20 de junho de 2016.

BARRETO, M. Turismo e Legado Cultural.São Paulo: Papirus, 2000.

BARTHOLO JUNIOR, R.S (coord.); CAMPOS, A.; BURSZTYN, I; EGREJAS, M.; LIMA, R.P. Marco referencial teórico para o Turismo de Base Comunitária. Relatório Técnico-Científico. Laboratório de Tecnologia e Desenvolvimento Social. Universidade Federal do Rio de Janeiro, 2011.

BARTHOLO JUNIOR, R.S. Sobre o sentido da proximidade: implicações para um turismo situado de base comunitária. BARTHOLO JUNIOR, R.S, SANSOLO D.G; BURSZTYN, I. Turismo de Base Comunitária: diversidade de olhares e experiências brasileiras. Letra e Imagem\Ministério do Turismo, 2009.

BEETON, S. (2006). Sustainable tourism in practice: trails and tourism. Critical management issues of multi-use trails. Tourism and Hospitality Planning \& Development, v.3, n.1, p.47-64, 2006.

CARMO, M.E. Preservação do patrimônio ferroviário em Minas Gerais. Dissertação de mestrado, Escola de Arquitetura - Universidade Federal de Minas Gerais, Belo Horizonte, 2014.

CAVALCANTE, J.E.R. Direitos culturais e direitos humanos: uma leitura à luz dos tratados internacionais e da constituição federal. Revista eletrônica DÍKE, v.1, n.1, p.1-26, 2006.

CORIOLANO, L.N.M.T. Turismo: prática social de apropriação e de dominação de territórios. In: LEMOS, A.G.; ARROYO, M.; SILVEIRA, M. (orgs). América Latina: cidade, campo e turismo. São Paulo: Clacso, 2006, p.367-378.

FREITAS, C.L. Turismo, política e planejamento - estudo do Circuito Turístico do Diamante no Vale do Jequitinhonha, em Minas Gerais. 2008. 388f. Tese (Doutorado em Geografia) - Instituto de Geociências. Universidade Federal de Minas Gerais, Belo Horizonte.

GIESBRECHT, R.M. Estações Ferroviárias do Brasil. 2015. Disponível em: http://www.estacoesferroviarias.com.br/efcb mg ramais/diamantina.htm. Acesso em: 04 de julho de 2016.

MAMEDE, D.M.;VIEIRA, G.L; SANTOS, A.P. Trens turísticos e patrimônio cultural: como o turismo ferroviário tem resgatado, preservado e valorizado o patrimônio cultural. Caderno Virtual de Turismo, v.8, n.2, p.82-94, 2008.

MARTíN, M. Las líneas férreas desmanteladas en Andalucía: Diagnóstico para su uso como itinerarios no monotorizados. Observatorio Medioambiental, v.17, p.299-324, 2014. 
MARTINS, M. A crise dos negócios do diamante e as respostas dos homens de fortuna no Alto Jequitinhonha, décadas de 1870-1890.Estudos Econômicos, 38(3), p.611-638, 2008.

MENDONÇA, T.C.M.; IRVING. M.A. Turismo de base comunitária: a participação como prática no desenvolvimento de projetos turístico no BrasilPrainha Do Canto Verde, Beberibe (CE). Caderno Virtual de Turismo, v.4, n.4, p.12-28, 2004.

MOORE, R.L., GITELSON, R. J.; GRAEFE, A.R. The economic impact of rail-trails. Journal of Park and Recreation Administration, v.12, n.2, p.6372, 1994.

LUDKE, M.; ANDRÉ, M.E.D. Pesquisa em educação: abordagens qualitativas. São Paulo: Editora Pedagógica e Universitária, 1986.

PAES, M.T.D. Patrimônio cultural, turismo e identidades territoriais: um olhar geográfico. In: BARTHOLO JUNIOR, R.S, SANSOLO D.G; BURSZTYN, I. Turismo de Base Comunitária: diversidade de olhares e experiências brasileiras. Letra e Imagem\Ministério do Turismo, 2009.

PALHARES, G.L.Transportesturísticos. São Paulo: Aleph, 2002.

PAULA, D.A. As ferrovias no Brasil: análise do processo de erradicação de ramais. In: Siglo y medio de ferrocarriles en Madrid: actas do II Congreso de Historia Ferroviaria, Aranjuez, 7-9 Fev. 2001.

PORTUGUEZ, A.P. Turismo, memória e patrimônio cultural. São Paulo: Roca, 2004.

PROCHNOW, L. N. O Iphan e o patrimônio ferroviário: a memória ferroviária como instrumento de preservação. Dissertação de Mestrado, Instituto do Patrimônio Histórico e Artístico Nacional-IPHAN, Rio de Janeiro, 2014.

REIS, A.C; JELLUM, C. Rail trails development: a conceptual model for sustainable tourism. Tourism Planning andDevelopment,v.9, n.2, p.133148, 2012.

SAMPAIO, C.A.C.; OYARZÚM, E. Arranjo Socioprodutivo Local de Base Comunitária: Análise Comparativa de Experiências de Turismo Comunitário no Brasil e no Chile. Blumenau: mimeo, 2006.

SANSOLO, D.G.; BURSZTYN, I. Turismo de Base Comunitária: potencialidade no espaço rural brasileiro. In: BARTHOLO JUNIOR, R.S.; SANSOLO DG; BURSZTYN I. Turismo de Base Comunitária: diversidade de olhares e experiências brasileiras. Letra e Imagem\Ministério do Turismo, 2009.

SANTOS, A.M. Entrevista concedida Rosália Aparecida Moreira. Diamantina, 25 mai. 2015.

SILVA, R.A.R. Patrimônio ferroviário brasileiro: da inclusão à exclusão de uma paisagem cultural. In: Paisagem cultural, patrimônio e projeto: anais do 3ํㅡㄴ Colóio Ibero Americano Paisagem Cultural, Patrimônio e Projeto. Belo Horizonte, 15-19 set. 2014. 
SILVEIRA, M.R. A importância geoeconômica das estradas de ferro no Brasil. Tese de Doutorado, Faculdade de Ciência e Tecnologia, Universidade Estadual Paulista, Presidente Prudente, 2003.

SOUZA, J.M. Cidade: momentos e processos. Serro e Diamantina na formação do Norte mineiro no século XIX. São Paulo: ANPOCS/Marco Zero, 1993.

\section{Notas:}

${ }^{1}$ Casas onde os funcionários da rede ferroviária moravam, estas eram construídas próximas das estações ou na metade do caminho entre uma estação e outra para que fosse possível dar manutenção aos trilhos (GIESBRECHT, 2015).

${ }^{2}$ A Agência de Desenvolvimento Regional de Turismo do Circuito dos Diamantes, a partir de 2010, passou a ser denominada de Circuito Turístico dos Diamantes. É uma entidade privada, sem fins lucrativos, constituída por associados da iniciativa privada e do poder público, com o papel de coordenar o desenvolvimento da atividade turística em âmbito regional. O Circuito Turístico dos Diamantes é sediado em Diamantina e abrange 13 municípios do Alto Jequitinhonha (FREITAS, 2008).

${ }^{3}$ Curralinho é o antigo nome de Corinto, cidade de Minas Gerais (GIESBRECHT, 2015).

Rosalia Aparecida Moreira: Universidade Federal dos Vales do Jequitinhonha e Mucuri, MG, Brasil.

E-Mail: rosaliaamoreira@gmail.com

Link para o currículo Lattes: http://lattes.cnpq.br/8848838151444156

Hugo Rodrigues Araújo: Universidade de Lisboa, Lisboa, Portugal.

E-Mail: hugoaraujo@msn.com

Link para o currículo Lattes: http://lattes.cnpq.br/9305503365859375

Data de submissão: 31 de agosto de 2016

Data de recebimento de correções: 12 de outubro de 2016

Data do aceite: 15 de outubro de 2016

Avaliado anonimamente 